\title{
Impact of Internet Usage on Undergraduate Academic Performances (Special Reference to You Tube Online Video Platform Usage)
}

Abstract- The study focuses on the undergraduates' academic performance and influence from YouTube. Non probability convenient sampling method has been utilized to select the sample. The sample included 60 undergraduates from a leading higher educational institute in Sri Lanka, representing three faculties (Business, Engineering and Computing). To collect the data, both quantitative and qualitative methods were used (in-dept. interview \& questioners). Based on past literature, conceptual framework is derived. Through the indepth interview, reasons behind the excessive usage of YouTube are found. Usage patterns of You Tube are identified by using quantitative methods and identified that how its impact on undergraduate academic performance. Based on the findings of the study reveals that undergraduates primarily use YouTube as a mode of entertainment while few are using YouTube to enhance their knowledge in academic activities.

Keywords: youtube, excessive usage, purpose, influence.

GJMBR-G Classification: JEL Code: L89

Strictly as per the compliance and regulations of:

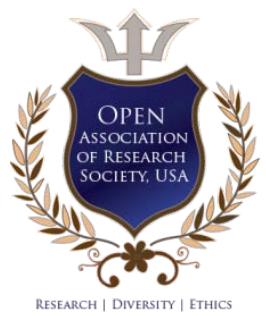

(C) 2020. W.D.N Madhavika \& R. M. N. M. Rathnayake. This is a research/review paper, distributed under the terms of the Creative Commons Attribution-Noncommercial 3.0 Unported License http://creativecommons.org/licenses/by-nc/3.0/), permitting all noncommercial use, distribution, and reproduction in any medium, provided the original work is properly cited. 


\title{
Impact of Internet Usage on Undergraduate Academic Performances (Special Reference to You Tube Online Video Platform Usage)
}

\author{
W.D.N Madhavika ${ }^{\alpha} \&$ R. M. N. M. Rathnayake $^{\sigma}$
}

\begin{abstract}
The study focuses on the undergraduates' academic performance and influence from YouTube. Non probability convenient sampling method has been utilized to select the sample. The sample included 60 undergraduates from a leading higher educational institute in Sri Lanka, representing three faculties (Business, Engineering and Computing). To collect the data, both quantitative and qualitative methods were used (in-dept. interview \& questioners). Based on past literature, conceptual framework is derived. Through the indepth interview, reasons behind the excessive usage of YouTube are found. Usage patterns of You Tube are identified by using quantitative methods and identified that how its impact on undergraduate academic performance. Based on the findings of the study reveals that undergraduates primarily use YouTube as a mode of entertainment while few are using YouTube to enhance their knowledge in academic activities.
\end{abstract} Keywords: youtube, excessive usage, purpose, influence.

\section{INTRODUCTION}

Y ouTube is one of the most popular Online Video Platform (OVP). It allows users to view, upload, share, rate, comment on videos. This online video platform spreads over the world within a very short period. And also, students today are more digitaloriented and driven by pre-information age (Almobarraz, 2018).

This study aims to find YouTube usage patterns and the excessive usage of YouTube at the level of undergraduates. As a generation of hyper-connected learners, they consider Web-based technologies integral to generate content on You Tube, well match for use in the classroom for a several reasons. YouTube has a huge content library that provides instructors with an unlimited library from which the users can choose. The average YouTube user spends between 15 to 25 minutes on the site, posting videos, watching videos and, providing video feedback. The population analysis of YouTube users aligns with college-aged students quite well. $37 \%$ of users are between the ages of 18 to 34 , which is the biggest age combination of any segment. Therefore, students are likely to be familiar with the receptive to view You Tube videos. Therefore a huge number of undergraduates use YouTube for their

Author $\alpha$ : Assistant Lecturer Department of Information Management Faculty of Business. e-mail: naduni.m@sliit.lk

Author $\sigma$ : Academic Instructor Department of Business Management Faculty of Business. academic purposes and non-academic purposes. Nonacademic purposes mean most of the time, undergraduates use YouTube for stress releasing and entertainment purposes. As academic purposes of undergraduates, use YouTube platform as an aid in coming up with creative assignments, projects and many more academic works.

\section{Literature Review}

At the very beginning, You Tube is beneficial for students as a learning tool, as well as being a vital tool for teaching several skills and tasks in a formal setting or at home (Almobarraz, 2018). In addition to that it was found that the usage of YouTube in the classroom had a positive impact on the overall engagement of students and their behavioural, emotional and cognitive engagement (Almobarraz, 2018). However, More N. (2015) argued that student engagement enhance the educational experience of online learners, in particular suggesting that the course delivery method should be considered when making decisions about the use of online videos and video sharing services.

YouTube has also been found to be the best fit to the characteristics of the next generation (student raised since the introduction of the World Wide Web) of digital learners and a valid approach to tap their multiple intelligences and learning styles (More N. , 2015)

The possible usages of YouTube in the educational process, stating that YouTube videos can be used directly in the classroom as part of the teaching process. They can be used to introduce new concepts, display information during instruction, or at the end of the lesson to confirm number one points. YouTube videos can also be used as an educational resource, where the teacher uses the video as a model for classroom activities and discussions. (Al Zboun, 2018)

YouTube videos increase student engagement, critical awareness and facilitated for deep learning. Furthermore, these videos could be accessed at any time of the day and from a place to suit the students. Apart from that, YouTube is also used to illustrate theoretical content, involve students, and inspire innovative teaching methods. They recommended faculty member to use this technology to stimulate student discussions, share information, and create a learning community. (June, 2014) 
HO: There is no relationship between YouTube usage and Academic Performance

\section{Research Approach}

\section{a) Sample and data collection procedure}

The survey was prepared based on the value of the YouTube service and how it influences students' academic performance. The main objective of the study is to determine usage patterns of YouTube. Based on the main objective designed a questionnaire, it consists with three sections.

1. Demographic information of the respondent

2. Information related to the usage patterns

3. Information related to excessive usage

The questionnaire includes close-ended questions which can directly identify the answer (e.g., How many times do you spend on YouTube?, How many YouTube videos do you watch in single sitting?) and Likert scale questions which respondents answered whether they agree, strongly agree, moderately agree, disagree and strongly disagree with the statement. Each option has a score, which can be used to analyse results. So it helped to identify their positioned place and to get support to do the analysis part correctly.

The sample was selected based on nonprobability convenient sampling method in which the sample size was 60 representing undergraduates from three faculties (Business, Computing and Engineering) in a Sri Lankan leading higher educational institute

Based on the interview approach, six students who has got addicted to YouTube were selected. The interview questions were mainly based on Moghavvemi's (2017) research paper and some moderations were done by the authors in order to match with the Sri Lankan context.

\section{b) Data analysis}

The participants were asked to fill out a paperbased survey and the data were collected from 60 students. Then collected data was analyzed through descriptive statistics via IBM SPSS version 22. Then using correlation and regression analysis, the relationship between variables were tested based on the mean value of the usage pattern of YouTube by undergraduates.

\section{Data Analysis Result/ Findings}

\section{a) Qualitative Results}

In the interview session, main focus was on the excessive usage of YouTube.

Q1: For what purpose do you use YouTube?

Q2: Why do you excessively use YouTube?

For the $1^{\text {st }}$ question, "or what purpose you use YouTube?" a majority of students give the same answer, which was that they use YouTube for entertainment and academic purposes. 5 out of 6 students gave the same answer while one said that he uses YouTube only for entertainment purposes.

$2^{\text {nd }}$ Question "Why do you excessively use YouTube?" students came up with different answers as follows.

- 1: "because it helps me to pass the time and get rid of loneliness. Most of the time, I'm stuck at the boarding; not only YouTube every social media helps me to rid of the loneliness".

- 2: "I quickly get stressed when doing the hard work, YouTube is the only solution for me to release my stress by listening to calm music videos and some kind of funny videos and all".

- 3: "I would like to watch, what's the new in the world, exploration in technology it gives me pleasure. And when I'm watching videos, I lose track of time because YouTube suggest recommended videos for me, so I'm also going through those videos".

- 4: "When I'm in boarding, I got family sick. Because I'm new for this environment. For reducing that feeling, I go for videos on YouTube; it gives me a perfect time. YouTube has categorical videos; we can go for which we want".

- 5: "I use YouTube for academic and also entertainment purposes, but when I have a stress feeling, I use that as a stress release tool. In that case, I excessively use YouTube; I lose track of time".

- 6: "I use YouTube for entertainment and also clear my mind. Usually, when l'm waking up in the morning, I go for my subscribed videos on YouTube. Now that takes a part of my life".

Based on the above answers, it can be concluded that most of the students excessively use YouTube to release their stress and to let go of the Ioneliness feeling. 
b) Quantitative Results

GPA frequency

Table 1: GPA Frequency

\begin{tabular}{|cc|c|c|c|c|}
\hline & Frequency & Percent & Valid Percent & $\begin{array}{c}\text { Cumulative } \\
\text { Percent }\end{array}$ \\
\hline \multirow{4}{*}{ Valid } & $3.6-4$ & 2 & 3.3 & 3.3 & 3.3 \\
& $3.0-3.5$ & 21 & 35.0 & 35.0 & 38.3 \\
& $2.0-2.9$ & 36 & 60.0 & 60.0 & 98.3 \\
& Below 2 & 1 & 1.7 & 1.7 & 100.0 \\
& Total & 60 & 100.0 & 100.0 & \\
\hline
\end{tabular}

In the sample, $60 \%$ of the undergraduates are in the GPA level between $2.0-2.9$.

Table 2: Descriptive Statistics of GPA

Descriptive Statistics

\begin{tabular}{|c|c|c|c|c|c|}
\hline & N & Minimum & Maximum & Mean & Std. Deviation \\
\hline Average GPA & 60 & 1.00 & 3.80 & 2.9042 & .53189 \\
Valid N (listwise) & 60 & & & & \\
\hline
\end{tabular}

The average GPA of the sample selected is 2.9042 , which seems to be in fairly good level at terms of academic performance.

Gender frequency

Table 3: Gender Frequency

Male and Female

\begin{tabular}{|c|c|c|c|c|c|}
\hline & & Frequency & Percent & Valid Percent & $\begin{array}{c}\text { Cumulative } \\
\text { Percent }\end{array}$ \\
\hline Valid & $\begin{array}{c}\text { Female } \\
\text { Male } \\
\text { Total }\end{array}$ & $\begin{array}{l}28 \\
32 \\
60\end{array}$ & $\begin{array}{c}46.7 \\
53.3 \\
100.0\end{array}$ & $\begin{array}{c}46.7 \\
53.3 \\
100.0\end{array}$ & $\begin{array}{c}46.7 \\
100.0\end{array}$ \\
\hline
\end{tabular}

In the sample out of 60 undergraduates, 28 were represented by female $46.7 \%$ from the sample, while $53.3 \%$ were males.

Age frequency

Table 4: Age Frequency

\begin{tabular}{|c|c|c|c|c|c|}
\hline & & Frequency & Percent & Valid Percent & $\begin{array}{c}\text { Cumulative } \\
\text { Percent }\end{array}$ \\
\hline \multirow{4}{*}{ Valid } & $16-20$ & 8 & 13.3 & 13.3 & 13.3 \\
\hline & $21-25$ & 48 & 80.0 & 80.0 & 93.3 \\
\hline & $26-30$ & 4 & 6.7 & 6.7 & 100.0 \\
\hline & Total & 60 & 100.0 & 100.0 & \\
\hline
\end{tabular}




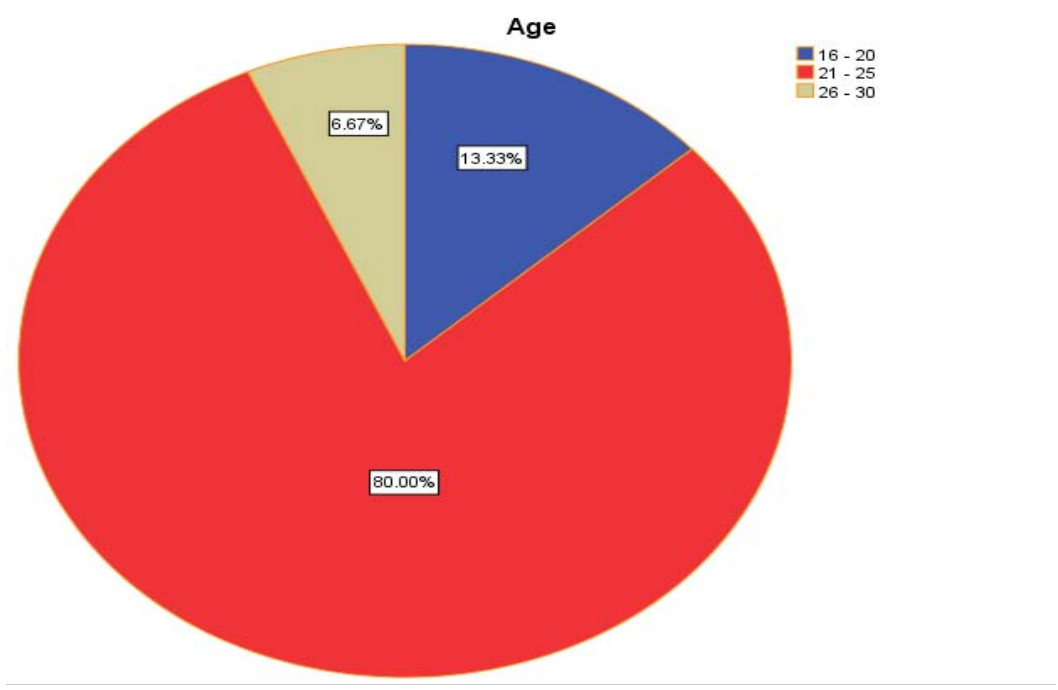

The questionnaire consisted of three age categories like $16-21,21-25$ and 26-30 age group. As percentages highest (80\%) goes to $21-25$ age group, and lowest (6.7\%) goes to $26-30$ age group.

\section{Usage patterns}

\section{Table 5: Frequency Patterns}

Descriptive Statistics

\begin{tabular}{|c|c|c|}
\hline & N & Mean \\
\hline Time spend on YouTube & 60 & 2.13 \\
Frequency on videos & 60 & 2.47 \\
How often do you visit & 60 & 2.12 \\
YouTube & 60 & \\
Valid N (listwise) & & \\
\hline
\end{tabular}

\section{Frequency patterns}

i.e. ("Time spend per day" $1=$ less than 1 hour/ $2=2$ to 3 hours/ $3=3$ to 4 hours/ $4=4$ to 5 hours $/ 5=$ more than 5 hours) ("Frequency on videos" $1=0$ to 5 videos/ $2=5$ to 10 videos/ $3=10$ to 15 videos $/ 4=15$ to 20 videos $/ 5=$ more than 20 videos) ("How often they visit" 1,2,3,4 \& 5 in order to Always, Usually, Sometimes, Rarely \& Never)

Based on data collected, it was observed that the students watch 5 to 10 videos in YouTube at one most of the students usually explore 2 to 3 hours (per sitting. day) by spending their time on YouTube and majority of

Type of videos

Table 6: Type of Videos

Descriptive Statistics

\begin{tabular}{|c|c|c|}
\hline & N & Mean \\
\hline I watch Educational videos & 60 & 2.48 \\
On YouTube & 60 & 3.40 \\
I watch Movies on YouTube & & \\
I watch Sport videos on \\
YouTube & 60 & 3.48 \\
\hline
\end{tabular}




\begin{tabular}{|c|c|c|}
\hline $\begin{array}{c}\text { I watch Comedy videos on } \\
\text { YouTube }\end{array}$ & 60 & 2.75 \\
I watch Gossip videos on \\
$\begin{array}{c}\text { YouTube } \\
\text { Valid N (listwise) }\end{array}$ & 60 & 3.70 \\
\hline
\end{tabular}

i.e. (Those all types of videos measured as a liker scale, in here we use $1=$ Always/2=usually/ 3=Sometimes/ $4=$ rarely $/ 5=$ Never)

Based on the above, most of the students usually watch Educational videos. Sometimes they watch Comedy, Movies\& Sports videos in YouTube and Purpose of using YouTube rarely watch gossip videos via YouTube.

Table 7: Purpose of using YouTube

\begin{tabular}{|c|c|c|}
\hline & $\mathrm{N}$ & Mean \\
\hline I use YouTube for & 60 & 1.97 \\
\hline $\begin{array}{l}\text { I use YouTube for Stress } \\
\text { release }\end{array}$ & 60 & 2.35 \\
\hline $\begin{array}{l}\text { I use YouTube for improve } \\
\text { English }\end{array}$ & 60 & 2.58 \\
\hline I use YouTube for as a hobby & 60 & 2.83 \\
\hline Valid N (listwise) & 60 & \\
\hline
\end{tabular}

i.e. (Those all types of videos measured as a liker scale, in here we use $1=$ strongly agree/ $2=$ Agree $/ 3=$ Moderate/ $4=$ Disagree $/ 5=$ strongly disagree)

Here most of the student use YouTube for their educational purpose (1.97) \& Stress release (2.35) Multiple Regression Analysis equally. Based on the findings, students have fewer usage of YouTube for English improvement as a hobby.

Table 8: Regression analysis of Frequency Coefficients ${ }^{\mathbf{a}}$

\begin{tabular}{|c|c|c|c|c|c|c|}
\hline & \multirow[t]{2}{*}{ Model } & \multicolumn{2}{|c|}{ Unstandardized Coefficients } & $\begin{array}{c}\text { Standardized } \\
\text { Coefficients }\end{array}$ & \multirow[t]{2}{*}{$t$} & \multirow[t]{2}{*}{ Sig. } \\
\hline & & B & Std. Error & Beta & & \\
\hline \multirow[t]{4}{*}{1} & (Constant) & 3.151 & .358 & & 8.810 & .000 \\
\hline & Time spend on YouTube & -.108 & .073 & .212 & 1.467 & .004 \\
\hline & Quantity of videos & -.136 & .063 & -.340 & -2.157 & .005 \\
\hline & $\begin{array}{c}\text { How often do you visit } \\
\text { YouTube }\end{array}$ & -.067 & .104 & -.099 & -.648 & .003 \\
\hline
\end{tabular}

a. Dependent veriable:Average GPA

The dependent variable is taken as GPA whereas independent variables are time spent, a number of videos watched, how often visit YouTube. All three independent variables are proved to have a significant relationship with the GPA since the p-value for all three variables are less than 0.05 . Based on the multiple regression analysis, the equation illustrating the relationship between academic performance (GPA) and the three independent variables (time spent, number of videos watched, how often YouTube is visited) is derived as follows. 
GPA (Academic Performance) $=3.151-.108$ (Time spent on YouTube)-0.136(Number of videos watched on YouTube perday) - 0.067(Number of times YouTube is visited per day).

Based on the derived equation, it is visible that there is a negative relationship between the academic performance, and number of videos watched, time spent on YouTube and number of times visited YouTube per day. Thus, it suggests that there seems to be a statistically significant negative relationship between the YouTube usage and academic performance of Sri Lankan undergraduates.

\section{Discussion}

The study focused on the importance of YouTube for Sri Lankan undergraduates and its impact on their academic performances. Based on the analysis, it was found that there is a statistically significant negative relationship between YouTube usage and academic performances of an undergraduate. Moreover, due to the impact of independent variables (time spent, number of videos watched, how often YouTube is visited) there is a significantly negative impact on the GPA of the undergraduate. To explore the reasons for excessive use of YouTube, 6 in-depth interviews were conducted, and through the interviews it was found that most of the students excessively use YouTube, to release their stress and to let go of the loneliness feeling. Linking to the past literature the same result can be found. Further it has proven through a study conducted Malaysia (Moghavvemi, 2017).

Based on the study, YouTube usage patterns of the study (quantitative analysis) were determined. The study found that most of the undergraduates use YouTube for educational purposes rather than to watch the videos on Gossips. Yet, based on the qualitative analysis, it was found that YouTube is the main source of stress releasing tool of the undergraduates who are boarded and away from their family. Also, it was found that there are some undergraduates use YouTube to improve their English knowledge as well.

\section{Vil. Conclusion}

YouTube is an interesting tool used by most of the undergraduates. Within the academic environment, to what extent it's use can enhance students learning methods has always been a doubt. As indicated by the present study, using YouTube as a learning tool has a great impact on student's academic performances. So the findings confirmed YouTube could be effectively integrated into performances because it allows students to be more cognitive as well as there is a significant impact on the academic achievement. Also, most of the undergraduates especially who are away from their families, use YouTube as the source of stress releasing.
Based on this research, it can be concluded that you tube is not negatively affecting on academic performances of undergraduates. Finally, the study suggests a future research opportunity in same study area under the topic of "Within the higher educational industry, how YouTube play anactive role as a teaching tool".

\section{References Références Referencias}

1. Al Zboun, M. G. (2018). The Impact of the Use of YouTube and Facebook on Students' Academic Achievement in Geography Course at the University of. Modern applied science, XII (03), 164-174.

2. Almobarraz, A. (2018). Utilization of YouTube as an information resource to support university courses. the Education Library, XXXVI(01), 71-81.

3. Alshuaibi, M. (2018). Use of social media, student engagement, and academic Performance of business students in Malayasia. International journal of Educational Management, XXXII (04), 625-640.

4. Bahian, P. (2016). YouTube usage and academic engagements of information technology students in Zamboanga Del Sur, Philippines. International journal of advanced research and development, I (06), 46-50.

5. Balbay, S. (2017). Students' Perceptions of the use of a YouTube channel specifically designed for an Academic Speaking Skills Course. Eurasian Journal of Applied Linguistics, III (02), 235-251.

6. Ensour, H. (2015). The Effect of Using YouTube on Youth Worst and Best Case. British journal of Applied Science \& Technology, VIII (03), 286-304.

7. Jackman, W. (2014). Students' Perspectives on Youtube Video Usage as an E-Resource in the University Classroom. J. Educational Technology Systems, XLII (03), 273-297.

8. June, S. (2014). Assessing the Use of YouTube Videos and Interactive Activities as a Critical Thinking Stimulator for Tertiary Students: An Action Research. International Education Studies., VII(08), 56-67.

9. Lai, K. (2013). How are our undergraduates using YouTube? A survey on music students' use of YouTube and the library's multimedia collection. Library Journal Artical, XVI (04), 199-217.

10. Moghavvemi, S. (2017). Facebook and YouTube Addiction: The Usage Pattern of Malaysian Student. Researcg Gate.

11. More, N. (2014). An Examination of Undergraduate student's Perceptions and Predilection of the use of YouTube in the Teaching and Learning Process. Interdisciplinary journal of E-Learning and learning objects, X, 17-32. 
12. More, N. (2015). Student Attitudes towards the Integration Of YouTube In Online, Hybrid, And WebAssisted Courses: An Examination Of The Impact Of Course Modality On Perception. MERLOY Journal of Online Learning and Teaching, XI (01), 55-73. 